\title{
Factors Affecting the Duration between Symptom Onset and Diagnosis in Patients with Gastric Cancer
}

\author{
Jianhao Yin, Yong Zhang, Jianguo Lai, Yao Tang, Lei Meng, Gang Xu, Haonan Wang, Chengxue Dang \\ Department of Oncology, First Affiliated Hospital of Xi'an Jiaotong University, Xi'an, China \\ Email: yin.jianhao123@stu.xjtu.edu.cn
}

How to cite this paper: Yin, J.H., Zhang, Y., Lai, J.G., Tang, Y., Meng, L., Xu, G., Wang, H.N. and Dang, C.X. (2016) Factors Affecting the Duration between Symptom Onset and Diagnosis in Patients with Gastric Cancer. Journal of Biosciences ana Medicines, 4, 42-53.

http://dx.doi.org/10.4236/jbm.2016.49005

Received: August 29, 2016

Accepted: September 27, 2016

Published: September 30, 2016

Copyright $\odot 2016$ by authors and Scientific Research Publishing Inc. This work is licensed under the Creative Commons Attribution International License (CC BY 4.0).

http://creativecommons.org/licenses/by/4.0/

\begin{abstract}
Background: The prognosis of patients with tumors is partly influenced by the stage when patients are diagnosed. Therefore, the time of confirmed diagnosis after onset can be considered as a prognostic predictor. Although a few of studies work on it, factors that influence the duration remain poorly understood in different areas. Methods: This retrospective study involved patients with gastric cancer. Participants completed questionnaires by either phone or face-to-face interviews. Results: Females are with a longer interval than males. Farms lived in rural area and with New Rural Cooperative Medical Scheme are associated with a longer time interval. Patients whose income is mainly from their spouses also have a longer interval. Abdominal pain seems to be associated with longer interval time, while vomiting leads to a shorter time interval. Taking medicine after symptoms appear is associated with longer time intervals, especially those take medicine nonstandardly and more than 2 weeks. Conclusions: The results demonstrate that the medical resource in rural area should still be enhanced; meanwhile taking medicine without doctor's advice should be cut down. Additional efforts must be made to devise strategies to properly guide patients' behavior.
\end{abstract}

\section{Keywords}

Gastric Cancer, Early Diagnosis, Diagnosis Delay, Help-Seeking Behavior

\section{Introduction}

According to the Chinese 3rd national cause of death survey, malignant tumor is the most common cause of death in urban areas and the second leading cause of death in rural areas [1]. Malignant tumors are also one of the primary causes of death worldwide and a statistic that appears to be on the rise [2] [3]. In China, no matter the morbidity 
or mortality, the gastric cancer is located in the top three. According to He et al., there were more than 400,000 patients with new-onset digestive tract tumors in 2011, accounting for over 300,000 deaths [4]. The 5-year survival rates for patients with gastric cancer are $27.4 \%$, underscoring the poor prognosis of it [5]. Unfortunately, patients with gastric cancer are often diagnosed when the disease is already at an advanced stage. In addition, these patients are more vulnerable to have poor responses to treatments such as chemotherapy and radiotherapy, which directly associate with poor prognosis. Therefore, early detection, diagnosis and treatment of digestive tract tumors are crucial for improving the prognosis of patients [6] [7].

Early in 1979, Safer et al. began to study the factors that influence the duration between symptom onset and diagnosis. In 1994, Belloc et al. investigated the duration between symptom onset and diagnosis for patients with digestive tract tumors [8] [9]. After the year 2000, the factors that influence the duration between symptom onset and diagnosis remain poorly understood [10]-[14]. A number of theoretical frameworks have been created to conceptualize the intervals between the different phases of decision-making [8] [15]. The early models included four intervals meant representing distinct stages of the decision-making process: "appraisal", "help-seeking", "diagnostic" and "pretreatment" [16]. Actually, cancer diagnosis is a complex and difficult task influenced by many factors that can differ from region to region. For example, when symptoms firstly appear, a patient's social context can influence the duration of time that elapses before they seek help [10]. The severity of the symptoms and the patient's attitude toward those symptoms can also lead the patient to either seek help early or wait for the symptoms to clear up [11]. Moreover, as tumors generally present with non-specific symptoms, doctors have to differentiate between patients whose symptoms are likely to be caused by tumors from those patients who require further evaluation, often with limited resources [13] [14].

Based on our observation in clinic, a variety of factors that may contribute to time of diagnosis as well as prognosis in America and Europe including income, gender, level of education and other factors are not that important for Chinese patients [17] [18]. In this study, we aimed to identify the time interval between the appearance of symptoms and diagnosis and the factors influencing the time interval in Chinese population.

\section{Patients and Methods}

In this retrospective study, we investigated patients with gastric cancer diagnosed at the First Affiliated Hospital of Xi'an Jiaotong University between 2009 and 2014. All personal data were obtained from patient interviews combined with a review of the hospital clinical records. Each patient was interviewed using a structured questionnaire by telephone or face-to-face. Informed consent for study participation and for access to medical records was obtained during the interview. In cases where the patient could not be interviewed, the questionnaire was completed by a close family member.

The questionnaire was divided into three parts: 1) personal and family information, including demographic characteristics and familial history of cancer [19];2) an inquiry 
into how long the respondent had been feeling unwell (a checklist was used to identify the type of symptom, and additional presenting symptoms were recorded) and the time interval between the initial symptoms and diagnosis; and 3) data concerning helpseeking actions the patient underwent prior to diagnosis [20]. Parts of questions are referred to the abroad study and the other is based on the condition of China. Although we hope there are as many patients as possible in the study, a total of 304 patients who agree to participate in the study completed their questionnaires.

The diagnosis intervals are presented as the median and 25 - 75 percentiles. Nonparametric tests were used to assess the relationship between the different types of symptom duration intervals and the observed variables. To avoid symptoms that could not be related to gastric cancer, no intervals greater than 24 months between symptom appearance and diagnosis were included; 34 patients (11.2\%) had intervals longer than 24 months. All statistical analyses were performed using SPSS v.20.0.

This study was approved by the Ethics Committee of the First Affiliated Hospital of Xian Jiaotong University.

\section{Results}

A total of 270 patients with gastric cancer were recruited for this study. Hospital record information was available for all patients. The median time intervals to diagnosis for gastric cancer is $6.0(5.0$ - 10.0) months. There are significant differences in symptom duration intervals were observed for the socio-demographic characteristics of Chinese patients. Females, living in rural area, New Rural Cooperative Medical Scheme (NRCM), farmers and relying on the spouses' revenue are associated with the longer time interval (Table 1), although other studies have reported that age, income group, drinking, smoking, medication history and familial history are associated with time interval [10] [20]-[22]. Concerning the initial symptoms, the presence of abdominal pain in patients with gastric cancer (Table 2) is associated with a longer time interval between symptom onset and diagnosis, while vomit is the opposite. There were no significant differences between the duration interval and the other symptoms. Meanwhile, when symptoms appear, we found that the help-seeking behaviors of patients also have an important influence on the duration interval (Table 3). Patients who taking medicine, particularly in a non-compliant fashion and taking medicine for long periods, are associated with longer time intervals between the symptom onset and diagnosis. Among all categories of medications, taking Chinese patent drug (CPD) in cases of gastric cancer was associated with longer intervals to diagnosis.

In our investigation, only 10 patients visited the hospital because their relatives ask them; this behavior is associated with a shorter interval. However, we also found that gastroscopy evaluations at the hospital were rare, being reported for only 31 patients. Counting out the X-ray and radiography because they were little taken, the gastroscope is associated with a shorter time between the onset of symptoms and diagnosis for patients with gastric cancer. These findings are consistent with previous studies to some extent [23] [24]. 
Table 1. Relationships between socio-demographic characteristics and diagnosis interval median (in months) of patients with gastric cancer.

\begin{tabular}{|c|c|c|}
\hline & \multicolumn{2}{|c|}{ Gastric Cancer } \\
\hline & N\% & DI Median \\
\hline \multicolumn{3}{|l|}{ Gender } \\
\hline Men & $220(81.5)$ & $6.0(4.0-10.0)$ \\
\hline Women & $50(18.5)$ & $9.0(6.0-12.0)$ \\
\hline $\mathrm{P}$ & \multicolumn{2}{|c|}{$<0.05$} \\
\hline \multicolumn{3}{|l|}{ Age Group } \\
\hline$\leq 50$ & $42(15.6)$ & $7.5(5.75-10.0)$ \\
\hline $51 \sim 65$ & $140(51.9)$ & $6.0(5.0-12.0)$ \\
\hline $66 \sim 75$ & $72(26.7)$ & $6.0(4.0-8.0)$ \\
\hline$>75$ & $16(5.9)$ & $6.0(4.0-9.0)$ \\
\hline $\mathrm{P}$ & \multicolumn{2}{|c|}{0.17} \\
\hline \multicolumn{3}{|l|}{ Level of Education } \\
\hline Illiterate & $5(1.9)$ & $9.0(5.5-12.0)$ \\
\hline Primary & $41(15.2)$ & $6.0(6.0-11.0)$ \\
\hline Secondary & $132(48.9)$ & $6.0(5.0-12.0)$ \\
\hline High School & $68(25.2)$ & $6.0(2.25-10.0)$ \\
\hline University & $24(8.9)$ & $4.5(1.0-6.75)$ \\
\hline $\mathrm{P}$ & \multicolumn{2}{|c|}{0.90} \\
\hline \multicolumn{3}{|l|}{ Residential Place } \\
\hline Metropolis & $56(20.7)$ & $5.0(1.0-9.75)$ \\
\hline Small Cities & $38(14.1)$ & $5.0(2.0-6.0)$ \\
\hline Fringe Area & $47(17.4)$ & $6.0(3.0-12.0)$ \\
\hline Rural Area & $129(47.8)$ & $8.0(6.0-12.0)$ \\
\hline $\mathrm{P}$ & \multicolumn{2}{|c|}{$<0.01$} \\
\hline \multicolumn{3}{|l|}{ Medical Insurance } \\
\hline Self-Supporting & $14(5.2)$ & $6.0(4.75-12.5)$ \\
\hline URBMI & $59(21.9)$ & $6.0(3.0-7.0)$ \\
\hline UEBMI & $31(11.5)$ & $6.0(2.0-12.0)$ \\
\hline NRCMS & $153(56.7)$ & $7.0(7.0-12.0)$ \\
\hline Others & $13(4.8)$ & $6.0(4.5-7.0)$ \\
\hline $\mathrm{P}$ & \multicolumn{2}{|c|}{0.01} \\
\hline \multicolumn{3}{|l|}{ Occupation } \\
\hline Farmer & $137(50.8)$ & $7.0(6.0-12.0)$ \\
\hline Worker & $57(21.1)$ & $6.0(3.5-9.5)$ \\
\hline Employee & $37(13.7)$ & $6.0(2.0-8.0)$ \\
\hline Others & $39(14.4)$ & $6.0(3.0-10.0)$ \\
\hline $\mathrm{P}$ & \multicolumn{2}{|c|}{$<0.05$} \\
\hline
\end{tabular}




\section{Continued}

Disposable Income

$\begin{array}{cr}<10,000 & 15(5.6) \\ 10,000 \sim 30,000 & 170(63.0) \\ 30,000 \sim 50,000 & 75(27.8) \\ 50,000 \sim 100,000 & 8(3.0) \\ >100,000 & 2(0.7) \\ P & \end{array}$

$8.0(5.0-12.0)$

$6.0(5.0-12.0)$

$6.0(4.0-10.0)$

$5.5(1.25$ - 10.50)

5.5

Revenue Sources

\section{Personal \\ Spouses'}

Children's

$\mathrm{P}$

Medical History

No
Yes
P

Medication History

No
Yes

P

Disease of Spouse

No
Yes
P

Family History

$\begin{array}{cc}\text { No } & 253(93.7) \\ \text { Yes } & 17(6.3)\end{array}$

$\mathrm{P}$

0.96

$6.0(3.5-10.0)$

$10.0(8.0-14.0)$

$6.0(5.0-10.0)$

$<0.05$

96

$$
6.0(5.0 \text { - 12.0) }
$$$$
6.0(2.0-10.0)
$$

0.28

$$
\begin{aligned}
& 6.0(5.0-12.0) \\
& 6.0(4.5-8.0)
\end{aligned}
$$

0.54

$6.0(5.0-12.0)$

$6.0(4.5-7.0)$

0.15

URBMI = Urban Resident Basic Medical Insurance, UEBMI = Urban Employee Basic Medical Insurance, NRCMS = New Rural Cooperative Medical Scheme; Some negative results are not listed in the table.

Table 2. Relationships between symptom presentation and diagnosis interval median (in months) of patients with gastric cancer.

\begin{tabular}{ccccc}
\hline Symptom & Abdominal Pain & Ventosity & Acid Regurgitation & Vomit \\
\hline N\% & $147(54.4)$ & $106(39.3)$ & $32(11.9)$ & $23(8.5)$ \\
DI Median & $6.0(5.0-12.0)$ & $6.0(5.0-10.0)$ & $6.0(3.25-11.5)$ & $6.0(3.0-6.0)$ \\
$\mathrm{p}$ & 0.02 & 0.79 & 0.80 & 0.01 \\
\hline
\end{tabular}


Table 3. Relationships between help-seeking behavior and diagnosis interval median (in months) of patients with digestive tract tumors.

\begin{tabular}{|c|c|c|}
\hline & \multicolumn{2}{|c|}{ Gastric Cancer } \\
\hline & N\% & DI Median \\
\hline \multicolumn{3}{|l|}{ Help-Seeking Behavior } \\
\hline Wait for Clear-Up & $80(29.6)$ & $6.0(4.0-11.5)$ \\
\hline Take Medicine & $87(32.2)$ & $8.0(6.0-12.0)$ \\
\hline Visit a Doctor & $103(38.2)$ & $6.0(3.0-9.0)$ \\
\hline $\mathrm{P}$ & \multicolumn{2}{|c|}{0.01} \\
\hline \multicolumn{3}{|l|}{ Antibiotics } \\
\hline No & $256(94.8)$ & $6.0(5.0-10.0)$ \\
\hline Yes & $14(5.2)$ & $7.0(2.0-16.5)$ \\
\hline $\mathrm{P}$ & \multicolumn{2}{|c|}{0.81} \\
\hline \multicolumn{3}{|l|}{ Prokinetics } \\
\hline No & $241(89.3)$ & $6.0(5.0-11.0)$ \\
\hline Yes & $29(10.7)$ & $6.0(6.0-11.0)$ \\
\hline $\mathrm{P}$ & \multicolumn{2}{|c|}{0.98} \\
\hline \multicolumn{3}{|l|}{ PPI } \\
\hline No & $165(61.1)$ & $6.0(4.0-10.0)$ \\
\hline Yes & $105(38.9)$ & $6.0(6.0-12.0)$ \\
\hline $\mathrm{P}$ & \multicolumn{2}{|c|}{0.13} \\
\hline \multicolumn{3}{|l|}{$\mathrm{CPD}$} \\
\hline No & $170(630)$ & $6.0(4.0-10.0)$ \\
\hline Yes & $100(37.0)$ & $7.5(6.0-12.0)$ \\
\hline $\mathrm{P}$ & \multicolumn{2}{|c|}{0.04} \\
\hline \multicolumn{3}{|l|}{$\mathrm{TCM}$} \\
\hline No & $263(97.4)$ & $6.0(5.0-10.0)$ \\
\hline Yes & $7(2.6)$ & $10.0(6.0-12.0)$ \\
\hline$P$ & \multicolumn{2}{|c|}{0.72} \\
\hline \multicolumn{3}{|l|}{ Reading Instructions } \\
\hline No & $81(30.0)$ & $7.0(6.0-12.0)$ \\
\hline Yes & $6(2.2)$ & $7.0(4.25-11.5)$ \\
\hline $\mathrm{P}$ & \multicolumn{2}{|c|}{0.67} \\
\hline \multicolumn{3}{|c|}{ Standardized Medication } \\
\hline No & $79(29.2)$ & $8.0(6.0-12.0)$ \\
\hline Yes & $8(3.0)$ & $6.0(5.0-9.5)$ \\
\hline $\mathrm{P}$ & \multicolumn{2}{|c|}{0.01} \\
\hline
\end{tabular}


Continued

Dosing Time

$<1$ week

1 - 2 weeks

$>2$ weeks

$\mathrm{P}$

Reason for Going to the Hospital

Examination
Got Worse
New Symptom
Relative

Examination

No

Endoscopy

$\mathrm{P}$
4 (1.5)

$19(7.0)$

$64(23.7)$

$105(38.9)$

$101(37.4)$

$54(20.0)$

$10(3.7)$

$234(81.9)$

$31(11.5)$
$5.0(0-16.0)$

$6.0(5.0-6.0)$

$9.0(6.0-12.0)$

$<0.01$

$6.0(4.0-8.0)$

$7.0(6.0$ - 12.0)

$6.5(5.0-12.0)$

$5.0(0.75-6.0)$

0.01

$6.0(5.0-12.0)$

$5.0(3.0-8.0)$

0.04

CPD: Chinese patent drug includes herbal medicines based on Traditional Chinese medicine. Chinese patent drug generally consists of extracted condensed pills called tea pills, which are cooked into an herbal tea to make the pills; TCM: Traditional Chinese medicine is the theory of traditional Chinese herbal therapy. Each herbal medicine pre-scription is a cocktail of many substances, usually tailored to the individual patient.

\section{Discussion}

This comprehensive study explored the socio-demographic factors, symptom presentation and help-seeking behavior that affected the time interval of diagnosis for patients with gastric cancer. First of all, the median of our study is 6 months. Although there is no other study to compare the results, lacking therapy for half a year may be an important factor leading to a poor prognosis of the gastric cancer.

Most of previous studies which find there is difference between genders in the time interval point out that the females have longer time interval than males. This may be due to the tolerance for symptoms of females is better than that of males. Abroad studies also reported a longer symptomatic duration in patients from certain socio-economic groups (e.g., drinking, smoking, lower income and lower education) or with a family history of cancer [20] [25]-[28] . Our investigation is partly in accordance with them. Farmer, Rural Area and NRCMS are associated with longer time interval between symptom onset and diagnosis. Taking Chinese status quo into consideration, most of famers live in rural area and most of their medicare is NRCMS. Because of the lack of medical resource in rural area, this may be the reason of a longer interval time. Meanwhile, there are lots of studies that focus on the income of family, but rarely study the revenue sources of a family. The main income of parents' family from spouse could be considered that there is a gap between patients and their spouses and it brings a longer time interval to patients. From the side, this is an economical feature of patients. 
Ramos et al. and Broughton et al. have suggested that having relatives or friends who have experienced similar symptoms can actually lead to longer interval between symptom onset and diagnosis [10] [29]. However, our findings did not support these correlations [30] [31].

Regarding the role of symptoms in delayed diagnosis, the result of our study is similar to previous studies [11]. We confirm that vomiting shortens the time interval of diagnosis. That may because both of them could lead to a decline in life experience and they are apparently more severe than other symptoms. These are consistent with other studies [20] [32]. Some reports have also claimed that abdominal pain is also associated with a shorter time interval of diagnosis, but the result comes out differently in our study. The abdominal pain in our investigation leads to a longer time interval. Due to high incidence of chronic gastritis in China, abdominal pain is considered as a common abdominal symptom that is easily ignored by majority of people, and patients are reluctant to seek for medical help until situation becomes worse [26] [33].

Help-seeking behavior is a very important factor in all studies. But there is no difference between waiting for cleaning up and visiting doctors in time interval. When symptoms appear, there are controversies in different studies for whether visit doctors immediately. Some researchers believed visiting doctors as early as possible could shorten the time interval, while some considered too early visiting doctors could extend the time interval. This may be due to the different medical conditions. Taking medicine is also a factor rarely mentioned by research abroad, but it's an important factor for the diagnosis interval in China because it's easy for Chinese patients to get medicine to relieve symptoms. It clearly extended the diagnosis interval for patients. Furthermore, taking CPD could extend the diagnosis interval compared with other drugs for patients with gastrointestinal cancer. Indeed, CPD as a product of interdisciplinary isn't well controlled by doctors for both western medicine and traditional Chinese medicine. These could explain why taking medicine is associated with extended diagnosis interval in this study. This situation is exacerbated partially because government doesn't monitor strictly. In addition, patients in China may have a larger variety of drugs to choose than patients in other countries.

Meanwhile, we found endoscopy was associated with a shorter diagnosis interval for patients with gastric cancer. As previous studies have found that appropriate examinations could reduce the diagnosis interval, inappropriate examinations could not only be helpless but also could extend the interval [34] [35].

Our study had several limitations. First, we lacked a consistent methodology to precisely determine the date that the symptom(s) first appeared. The interpretation of bodily sensations as symptoms can be affected by many social and cultural variables, and respondents can be inconsistent at defining time intervals. Second, the patients surveyed were all from the First Affiliated Hospital of Xi'an Jiaotong University. Therefore, this study was a single-center survey and may not be representative of other regions. Finally, as the 5-year survival rate for digestive tract cancer was low, many patients died due to disease progression, therefore, the patients whom we surveyed had relatively 
good prognoses, and as such, our results may not accurately capture the severity and magnitude of the situation. Additional studies are required to address these issues.

Taking together, our findings highlight that patients will benefit from a shorter diagnosis interval if they go to the hospital after symptoms appear in China and the nation should strengthen the control of drug, especially CPD. Medicine should be taken according to instruction or doctors' prescription. Early hospital visits and appropriate examination are crucial to shorten the diagnosis interval and provide more opportunities for patients.

\section{Acknowledgements}

This study was partially supported by the National Natural Science Foundation of China (NSFC 81372280 to YZ).

\section{Conflict of Interest}

The authors declare no conflict of interest.

\section{References}

[1] Chen, Z. (2008) The Third National Retrospective Sampling Survey on Causes of Death. Peking Union Medical College Press, Beijing.

[2] Global Burden of Disease Cancer Collaboration (2015) The Global Burden of Cancer 2013. JAMA Oncology, 1, 505-527.

[3] Ferlay, J., Soerjomataram, I., Dikshit, R., Eser, S., Mathers, C., Rebelo, M., Parkin, D.M., Forman, D. and Bray, F. (2015) Cancer Incidence and Mortality Worldwide: Sources, Methods and Major Patterns in GLOBOCAN 2012. International Journal of Cancer, 136, E359-E386. http://dx.doi.org/10.1002/ijc.29210

[4] He, J. and Chen, W.Q. (2012) Chinese Cancer Registry Annual Report. Military Medical Science Press, Beijing.

[5] Zeng, H.M., Zheng, R.S., Guo, Y.M., Zhang, S.W., Zou, X.N., Wang, N., Zhang, L.M., Tang, J.G., Chen, J.G., Wei, K.G., Huang, S.Q., Wang, J., Yu, L., Zhao, D., Song, G., Chen, J.S., Shen, Y.Z., Yang, X.P., Gu, X.P., Jin, F., Li, Q.L., Li, Y.H., Ge, H.M., Zhu, F.D., Dong, J.L., Guo, G.P., Wu, M., Du, L.B., Sun, X.B., He, Y.T., Coleman, M.P., Baade, P., Chen, W.Q., Yu, X.Q. (2015) Cancer Survival in CHINA, 2003-2005: A Population-Based Study. International Journal of Cancer, 136, 1921-1930. http://dx.doi.org/10.1002/ijc.29227

[6] Barillari, P., de Angelis, R., Valabrega, S., Indinnimeo, M., Gozzo, P., Ramacciato, G. and Fegiz, G. (1989) Relationship of Symptom Duration and Survival in Patients with Colorectal Carcinoma. European Journal of Surgical Oncology, 15, 441-445.

[7] Yokota, T., Kunii, Y., Teshima, S., Yamada, Y., Saito, T., Takahashi, M., Kikuchi, S. and Yamauchi, H. (2000) Significant Prognostic Factors in Patients with Early Gastric Cancer. International Surgery, 85, 286-290.

[8] Safer, M.A., Tharps, Q.J., Jackson, T.C. and Leventhal, H. (1979) Determinants of Three Stages of Delay in Seeking Care at a Medical Clinic. Medical Care, 17, 11-29. http://dx.doi.org/10.1097/00005650-197901000-00002

[9] Belloc Calmet, J., Porta, S.M., MalatsRiera, N., Gallen Castillo, M. and Planas, D.J. (1994) El síntomainicialatribuible al cáncerenlostumores del tubodigestivo. Un análisis de concordancia entre el paciente y el médico. Medicina Clínica, 103, 401-407. 
[10] Ramos, M., Arranz, M., Taltavull, M., March, S., Cabeza, E. and Esteva, M. (2010) Factors Triggering Medical Consultation for Symptoms of Colorectal Cancer and Perceptions Surrounding Diagnosis. European Journal of Cancer Care, 19, 192-199. http://dx.doi.org/10.1111/j.1365-2354.2008.00998.x

[11] Mitchell, E., Macdonald, S., Campbell, N.C., Weller, D. and Macleod, U. (2008) Influences on Pre-Hospital Delay in the Diagnosis of Colorectal Cancer: A Systematic Review. British Journal of Cancer, 98, 60-70. http://dx.doi.org/10.1038/sj.bjc.6604096

[12] Jellema, P., van der Windt, D.A., Bruinvels, D.J., Mallen, C.D., van Weyenberg, S.J., Mulder, C.J. and de Vet, H.C. (2010) Value of Symptoms and Additional Diagnostic Tests for Colorectal Cancer in Primary Care: Systematic Review and Meta-Analysis. BMJ, 340, c1269. http://dx.doi.org/10.1136/bmj.c1269

[13] Adelstein, B.A., Macaskill, P., Chan, S.F., Katelaris, P.H. and Irwig, L. (2011) Most Bowel Cancer Symptoms Do Not Indicate Colorectal Cancer and Polyps: A Systematic Review. BMC Gastroenterology, 11, 65. http://dx.doi.org/10.1186/1471-230X-11-65

[14] Astin, M., Griffin, T., Neal, R.D., Rose, P. and Hamilton, W. (2011) The Diagnostic Value of Symptoms for Colorectal Cancer in Primary Care: A Systematic Review. British Journal of General Practice, 61, e231-e243. http://dx.doi.org/10.3399/bjgp11X572427

[15] Andersen, B.L., Cacioppo, J.T. and Roberts, D.C. (1995) Delay in Seeking a Cancer Diagnosis: Delay Stages and Psychophysiological Comparison Processes. British Journal of Social Psychology, 34, 33-52. http://dx.doi.org/10.1111/j.2044-8309.1995.tb01047.x

[16] Walter, F., Webster, A., Scott, S. and Emery, J. (2012) The Andersen Model of Total Patient Delay: A Systematic Review of Its Application in Cancer Diagnosis. Journal of Health Services Research \& Policy, 17, 110-118. http://dx.doi.org/10.1258/jhsrp.2011.010113

[17] Department of Health (2000) Referral Guidelines for Suspected Cancer. Department of Health, London.

[18] Ministerio de Sanidad y Consumo (2006) Estrategiaencáncer del sistemanacional de salud. Ministerio de Sanidad y Consumo, Madrid.

[19] Grupo de trabajo de la Sociedad Española de Epidemiologia y de la Sociedad Española de Medicina de Familia y Comunitaria (2000) Una propuesta de medida de la clase social. Atención Primaria, 25, 350, 354, 358, 362-352-356-360-363.

[20] De Nooijer, J., Lechner, L. and de Vries, H. (2003) Social Psychological Correlates of Paying Attention to Cancer Symptoms and Seeking Medical Help. Social Science \& Medicine, 56, 915-920. http://dx.doi.org/10.1016/S0277-9536(02)00098-9

[21] Hansen, R.P., Olesen, F., Sørensen, H.T., Sokolowski, I. and Søndergaard, J. (2008) Socioeconomic Patient Characteristics Predict Delay in Cancer Diagnosis: A Danish Cohort Study. BMC Health Services Research, 8, 49. http://dx.doi.org/10.1186/1472-6963-8-49

[22] Pedersen, A.F., Olesen, F., Hansen, R.P., Zachariae, R. and Vedsted, P. (2011) Social Support, Gender and Patient Delay. British Journal of Cancer, 104, 1249-1255. http://dx.doi.org/10.1038/bjc.2011.87

[23] Maguire, A., Porta, M., Malats, N., Gallén, M., Piñol, J.L. and Fernandez, E. (1994) Cancer Survival and the Duration of Symptoms. An Analysis of Possible Forms of the Risk Function. ISDS II Project Investigators, European Journal of Cancer, 30A, 785-792. http://dx.doi.org/10.1016/0959-8049(94)90293-3

[24] Marshall, J.R. and Funch, D.P. (1986) Gender and Illness Behavior among Colorectal Cancer Patients. Women's Health, 11, 67-82. http://dx.doi.org/10.1300/J013v11n03_06

[25] Korsgaard, M., Pedersen, L., Sørensen, H.T. and Laurberg, S. (2006) Reported Symptoms, Diagnostic Delay and Stage of Colorectal Cancer: A Population-Based Study in Denmark. 
Colorectal Disease, 8, 688-695. http://dx.doi.org/10.1111/j.1463-1318.2006.01014.x

[26] MacArthur, C. and Smith, A. (1984) Factors Associated with Speed of Diagnosis, Referral, and Treatment in Colorectal Cancer. Journal of Epidemiology and Community Health, 38, 122-126. http://dx.doi.org/10.1136/jech.38.2.122

[27] Vineis, P., Fornero, G., Magnino, A., Giacometti, R. and Ciccone, G. (1993) Diagnostic Delay, Clinical Stage, and Social Class: A Hospital Based Study. Journal of Epidemiology and Community Health, 47, 229-231. http://dx.doi.org/10.1136/jech.47.3.229

[28] Ratcliffe, R., Kiff, R.S., Hoare, E.M., Kingston, R.D., Walsh, S.H. and Jeacock, J. (1989) Early Diagnosis in Colorectal Cancer Still No Benefit? Annales de Chirurgie, 43, 570-574.

[29] Broughton, M., Bailey, J. and Linney, J. (2004) How Can Experiences of Patients and Carers Influence the Clinical Care of Large Bowel Cancer? European Journal of Cancer Care, 13, 318-327. http://dx.doi.org/10.1111/j.1365-2354.2004.00477.x

[30] Robertson, R., Campbell, N.C., Smith, S., Donnan, P.T., Sullivan, F., Duffy, R., Ritchie, L.D., Millar, D., Cassidy, J. and Munro, A. (2004) Factors Influencing Time from Presentation to Treatment of Colorectal and Breast Cancer in Urban and Rural Areas. British Journal of Cancer, 90, 1479-1485. http://dx.doi.org/10.1038/sj.bjc.6601753

[31] Neal, R.D. and Allgar, V.L. (2005) Sociodemographic Factors and Delays in the Diagnosis of Six Cancers: Analysis of Data from the "National Survey of NHS Patients: Cancer". British Journal of Cancer, 92, 1971-1975. http://dx.doi.org/10.1038/sj.bjc.6602623

[32] Majumdar, S.R., Fletcher, R.H. and Evans, A.T. (1999) How Does Colorectal Cancer Present? Symptoms, Duration, and Clues to Location. American Journal of Gastroenterology, 94, 3039-3045. http://dx.doi.org/10.1111/j.1572-0241.1999.01454.x

[33] Gonzalez-Hermoso, F., Perez-Palma, J., Marchena-Gomez, J., Lorenzo-Rocha, N. and Medina-Arana, V. (2004) Can Early Diagnosis of Symptomatic Colorectal Cancer Improve the Prognosis? World Journal of Surgery, 28, 716-720. http://dx.doi.org/10.1007/s00268-004-7232-8

[34] Young, C., Sweeney, J.L. and Hunter, A. (2000) Implications of Delayed Diagnosis in Colorectal Cancer. Australian and New Zealand Journal of Surgery, 70, 635-638. http://dx.doi.org/10.1046/j.1440-1622.2000.01916.x

[35] Esteva, M., Leiva, A., Ramos, M., Pita-Fernández, S., González-Luján, L., Casamitjana, M., Sánchez, M.A., Pértega-Díaz, S., Ruiz, A., Gonzalez-Santamaría, P., Martín-Rabadán, M., Costa-Alcaraz, A.M., Espí, A., Macià, F., Segura, J.M., Lafita, S., Arnal-Monreal, F., Amengual, I., Boscá-Watts, M.M. and Hospital, A. (2013) Factors Related with Symptom Duration Until Diagnosis and Treatment of Symptomatic Colorectal Cancer. BMC Cancer, 13, 87. http://dx.doi.org/10.1186/1471-2407-13-87 


\section{The Questionnaire about Factors Influencing the Duration between Symptom Onset and Diagnosis}

Thank you for participating in this study, the results are invisible for irrelevant personnel. Please complete the questionnaire truthfully.

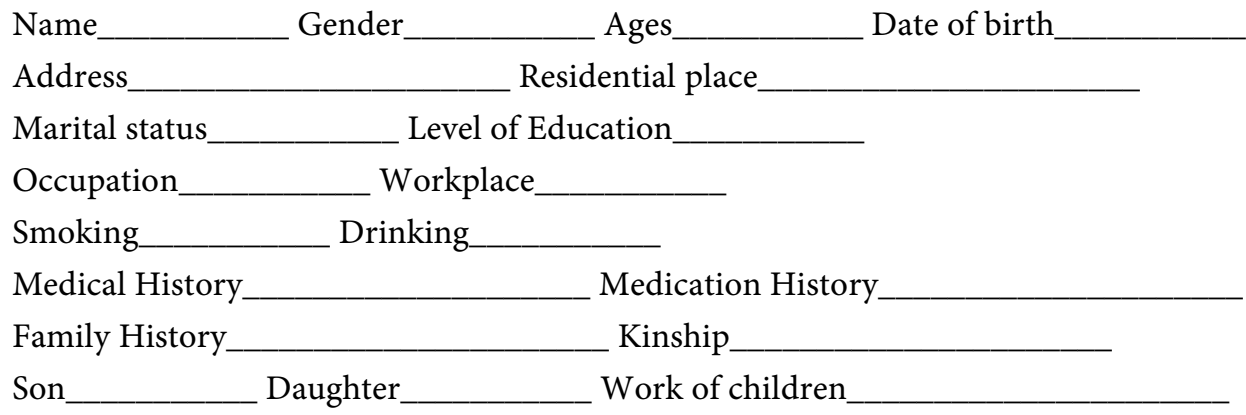

Disease of Spouse

Medical insurance Disposable income Revenue Sources

Time interval between symptoms onset and diagnosis

First symptom Help seeking behaviour First examination

The reason why did not take gastroscopy

The name of medicine

Sources of medicine Read instructions

Know about medicine Standardized Medication

The reason of non-compliant fashion Time of medication

Reason of visit a doctor for you:

Accepting pre-submission inquiries through Email, Facebook, LinkedIn, Twitter, etc.

A wide selection of journals (inclusive of 9 subjects, more than 200 journals)

Providing 24-hour high-quality service

User-friendly online submission system

Fair and swift peer-review system

Efficient typesetting and proofreading procedure

Display of the result of downloads and visits, as well as the number of cited articles

Maximum dissemination of your research work

Submit your manuscript at: http://papersubmission.scirp.org/

Or contact jbm@scirp.org 